
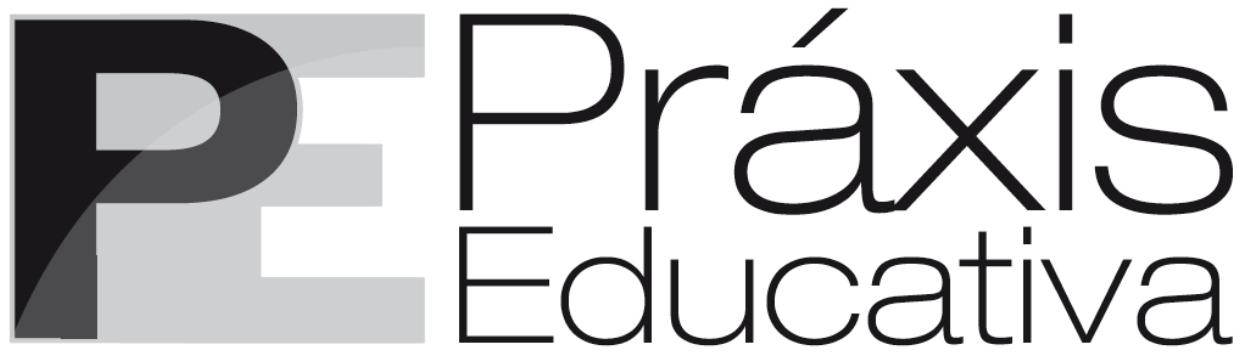

ISSN 1809-4309 (Versão online) DOI: 10.5212/PraxEduc.v.12i3.008

\title{
O que dizem os estudantes surdos da Universidade Federal de Santa Maria sobre a sua permanência no ensino superior
}

\author{
What deaf students from the Federal University of Santa Maria say about \\ their conditions of study in higher education
}

\section{Qué dicen los estudiantes sordos de la Universidad Federal de Santa María sobre su permanencia en la enseñanza superior}

\author{
Luiz Renato Martins da Rocha* \\ Lara Ferreira dos Santos ${ }^{* *}$
}

\begin{abstract}
Resumo: O presente artigo tem como objetivo principal descrever alguns resultados de investigação sobre como os estudantes surdos da Universidade Federal de Santa Maria, segundo sua própria percepção, têm sido atendidos em suas necessidades linguísticas e pedagógicas nos cursos de graduação. A escolha por tal instituição deve-se ao fato de possuir um exame de seleção por videogravação para a Língua Brasileira de Sinais (Libras), que a diferencia dos demais contextos universitários e, ainda, ter um número notável de estudantes surdos em comparação às demais realidades universitárias brasileiras. Trata-se de uma pesquisa do tipo descritiva e exploratória; a coleta de dados ocorreu por meio de aplicação de questionário eletrônico (online) a 18 estudantes surdos. Os resultados apontam que apesar do acesso diferenciado à Universidade, há muitas semelhanças em comparação aos demais contextos universitários. A partir disso, nas conclusões, verifica-se a manutenção da precariedade de condições para a permanência desses acadêmicos em sala de aula.
\end{abstract}

Palavras-chave: Estudantes surdos. Educação Superior. Permanência.

\begin{abstract}
This paper aims at describing some results from the investigation on how deaf students from the Federal University of Santa Maria, according to their own perception, have been assisted in their linguistic and pedagogical needs in the graduation courses. Their choice of this institution is due to the fact that it has a selection test for the Brazilian Sign Language (Libras, Brazilian Portuguese abbreviation) using video recording. This makes the institution have a greater number of deaf students when compared to other universities and creates an environment which is different from other university contexts. The study comprised descriptive and exploratory research; data collection was carried out through the application of an electronic questionnaire (online) to 18 deaf students. The results revealed that despite the differentiated access to this university, there are still many similarities when compared to other university contexts. The conclusions point out to the maintenance of precarious conditions for the permanence of these students in the classroom.
\end{abstract}

Keywords: Deaf students. Higher Education. Permanence.

\footnotetext{
*Universidade Tecnológica Federal do Paraná (UTFPR). E-mail: <luizrocha@utfpr.edu.br>.

${ }^{* *}$ Universidade Federal de São Carlos (UFSCar). E-mail: <larasantos.ufscar@gmail.com>.
} 
Resumen: El presente artículo tiene como objetivo principal describir algunos resultados de investigación sobre cómo los estudiantes sordos de la Universidad Federal de Santa María, según su propia percepción, han sido atendidos en sus necesidades lingüísticas y pedagógicas en los cursos de grado. La elección por tal institución se debe al hecho de ella poseer un examen de selección por videograbación para la Lengua Brasileña de Señales (Libras), diferente de los demás contextos universitarios y, aún, por tener un número notable de estudiantes sordos en comparación a las demás realidades universitarias brasileñas. Se trata de una investigación de tipo descriptivo y exploratorio; la recolección de datos ocurrió por medio de aplicación de cuestionario electrónico (online) a 18 estudiantes sordos. Los resultados apuntan que a pesar del acceso diferenciado a la Universidad, hay muchas semejanzas en comparación a los demás contextos universitarios. A partir de eso, en las conclusiones, se verifica el mantenimiento de la precariedad de condiciones para la permanencia de esos académicos en el aula.

Palabras clave: Estudiantes sordos. Educación universitaria. Permanencia.

\section{Introdução}

Os sujeitos surdos, por não terem acesso à Língua Portuguesa tal como os ouvintes, fazem uso, muitas vezes, da Língua Brasileira de Sinais (Libras) - uma língua de modalidade visuoespacial. $\mathrm{O}$ acesso às informações, para os sujeitos surdos, não se processa pela via auditiva, a compreensão de mundo e as interações se dão por meio de experiências visuais (BRASIL, 2005).

A educação das pessoas surdas e das demais pessoas público alvo da Educação Especial, passou por diferentes concepções ao longo dos anos, migrando de um modelo segregacionista para uma perspectiva inclusiva, o que pode ser evidenciado pela expansão da presença desse público nas instituições de educação formal, antes excluído por políticas públicas que não contemplavam suas diferenças linguísticas e culturais (ROCHA, 2015).

Em consequência de movimentos sociais das comunidades surdas e a fim de garantir o direito das pessoas surdas à educação, uma série de leis, decretos e resoluções foram criados ao longo dos últimos anos, assegurando o ingresso e a permanência (acesso ${ }^{1}$ ) desse público à Educação Básica e Superior. No entanto, ainda estamos distantes da efetivação do direito equitativo das pessoas surdas a um ensino de qualidade e que contemple as diferenças (LACERDA, 2006).

Atualmente, pouco se tem discutido sobre a permanência de surdos nas instituições de ensino superior (IES), o que se faz necessário, pois, "vencida a barreira do ingresso, o próximo desafio é a permanência no curso, que depende muito da mediação do intérprete" (BISOL, 2010, p. 151), o que, no entanto, nem sempre "resolverá todos os problemas, nem todas as questões específicas, nas relações entre professor/aluno e instituição de ensino" (DAROQUE; PADILHA, 2012, p. 31).

$\mathrm{Na}$ dissertação de Goularte (2014), a autora aponta que a permanência é um grande entrave vivenciado pelos alunos surdos na universidade, pois, majoritariamente, os professores planejam suas aulas pensando em alunos ouvintes, sem adequá-las nem se preocupar com o aluno surdo, que, muitas vezes, tem permanecido invisível na sala de aula.

\footnotetext{
1 “Cabe destacar que 'acesso' é compreendido de uma maneira ampla, ou seja, corresponde não só ao ingresso à universidade (por meio de um processo seletivo, justo e atento às necessidades dos alunos com deficiência), mas à permanência desse aluno na instituição (subsídios que garantam condições adequadas para a conclusão com sucesso do curso)" (CASTRO, 2011, p. 23).
} 
O que dizem os estudantes surdos da Universidade Federal de Santa Maria sobre a sua permanência...

Goularte (2014) esclarece que, "no acesso [à Universidade Federal de Santa Maria (UFSM), onde se dá a pesquisa], há todo um investimento na Libras para que o sujeito surdo seja capturado para ingressar na Universidade; após o ingresso, as estratégias mudam” (p. 86).

No artigo de Silva, Cymrot e D'Antino (2012), os autores aplicaram um questionário aos professores de dois câmpus de uma instituição particular paulista, sendo respondido por 752 $(53,9 \%)$ dos 1394 professores existentes na universidade, com o objetivo de "oferecer subsídios para a implementação de futuras ações afirmativas e política institucional favorecedoras do aprimoramento das condições de permanência desse alunado [de surdos]" (p. 667). Na visão da maioria desses professores (66,64\%), o intérprete de Libras é essencial ao longo do curso, porém, no momento de realização das provas na instituição, não veem tanta relevância na presença deste em sala $(51,7 \%)$. Quanto à flexibilização das provas escritas, valorizando seu conteúdo semântico, grande parte $(60,4 \%)$ acredita que tais adaptações não são necessárias; concernente à disponibilização de materiais para conhecer a especificidade do aluno surdo, 61\% acredita ser imprescindível.

Percebe-se, pelos dados obtidos por Silva, Cymrot e D'Antino (2012), que grande parte dos professores entende a importância do intérprete de Libras na universidade, porém, desconhece as especificidades linguísticas e de aprendizado dos surdos, o que gera entraves à permanência desses sujeitos e vai de encontro à legislação vigente (BRASIL, 2003; 2005; 2010), que orienta a realização de adaptações nos processos didáticos voltados aos surdos.

Ainda nessa perspectiva, o grande conflito que há em sala de aula entre aluno surdo, professor e colegas ouvintes deve-se à existência das "diferenças em relação à linguagem. Sua língua de reflexão é outra, e os meios para aprender os conteúdos novos são outros". (DAROQUE; PADILHA, 2012, p. 27). Nesse sentido, a pergunta norteadora para a realização da pesquisa aqui referida pode assim ser apresentada: quais as percepções dos estudantes surdos da Universidade Federal de Santa Maria (UFSM) sobre a sua permanência em sala de aula, na relação aluno surdo-professor, aluno surdo-intérprete de Libras e aluno surdo-aluno ouvinte?

A dissertação de Junior (2015), intitulada "A modelação de uma Politica Cooperativa na Formação de Estudantes Surdos no Ensino Superior", objetivou analisar a rede de interdependência na qual uma estudante surda encontrava-se envolvida no processo de formação, no curso de Pedagogia de uma Universidade Federal. Para isso, o autor debruçou-se sobre a compreensão do processo de acesso e permanência de estudantes nas IES brasileiras; a coleta de dados ocorreu por meio de observações e entrevistas com alunos ouvintes e surdos da sala de aula. Nesse contexto, concluiu a pesquisa afirmando que com a "matrícula de uma estudante surda, emergiu naquela turma a necessidade de criar outros modos de atuação docente, desenvolvendo-se estratégias didáticas que possibilitassem a comunicação entre os estudantes" (JUNIOR, 2015, p.131). Este caso revela que a cooperação e ajuda dos estudantes proporcionou à estudante surda a permanência de forma mais harmoniosa e interessante, diferentemente muitas vezes do que ocorre em salas onde há surdos.

A escolha pela UFSM justifica-se pelo fato de que a universidade possui um grande quantitativo de surdos em diferentes cursos de graduação e, nesta, o ingresso ocorria (até $2015^{2}$ ) por meio da videogravação do seu vestibular para a Libras e, ainda, a universidade possui um sistema de cotas para alunos com deficiência, reservando para eles 5\% das vagas (UFSM, 2015). Nos últimos cinco anos, cerca de 25 surdos foram aprovados por meio do vestibular em Libras (ROCHA, 2015).

\footnotetext{
2 A interrupção do vestibular videogravado em Libras deu-se em virtude da adoção do Exame Nacional do Ensino Médio (Enem) como única "porta” de acesso à UFSM.
}

Práxis Educativa, Ponta Grossa, v. 12, n. 3, p. 826-847, set./dez. 2017 Disponível em: <http://www.revistas2.uepg.br/index.php/praxiseducativa> 
O interesse pelas percepções dos estudantes surdos no que tange à sua permanência em sala de aula deve-se à necessidade de compreender sua relação com professores, intérpretes de Libras e alunos ouvintes, pois as "condições de permanecerem nas instituições requerem ações e serviços implementados com o objetivo de garantir a permanência desses estudantes nas instituições, obtendo [assim] sucesso acadêmico" (CASTRO, 2011, p. 134).

Objetivamos, desse modo, investigar como os estudantes surdos da UFSM são atendidos em suas necessidades linguísticas e pedagógicas nos cursos de graduação. De forma específica, pretendemos compreender como vem ocorrendo a relação aluno surdo-professor, aluno surdointérprete de Libras e aluno surdo-aluno ouvinte em sala de aula.

\section{Método}

A pesquisa aqui referida constituiu-se de um estudo do tipo descritivo e exploratório, buscando encontrar o problema, o objeto e o percurso metodológico para caracterizá-lo. Tal fase fez-se necessária por se tratar de "um tema pouco explorado, tornando-se difícil sobre ele formular hipóteses precisas e operacionalizáveis" (GIL, 2008, p. 27). Buscou-se, ainda, descrever “[...] as características de determinada população ou fenômeno ou o estabelecimento de relações entre variáveis" (Idem, p. 28).

O método de abordagem foi o indutivo, para que se pudessem alcançar os alicerces lógicos da investigação. Gil (2008, p. 10) descreve que: "O método indutivo procede inversamente ao dedutivo: parte do particular e coloca a generalização como um produto posterior do trabalho de coleta de dados particulares".

A compreensão de um fenômeno segundo a perspectiva do próprio sujeito é muito rica, e neste caso se buscou a percepção daqueles que estão vivenciando diariamente em sala de aula o processo de inclusão e permanência, isso é, dar vez e "voz" aos surdos e não somente consultar fontes secundárias para tecer conclusões a seu respeito.

\section{Coleta de dados: questionário eletrônico (online)}

A coleta de dados ocorreu por meio do questionário online, aprovado pelo Comitê de Ética $^{3}$ da Universidade Federal de São Carlos, em cujo Programa de Pós-Graduação em Educação Especial (PPGEEs) a pesquisa se realizou. Não procuramos, com esse questionário, verdades absolutas para descrever a realidade, mas conhecer, mesmo que minimamente, versões da realidade.

O questionário online pode ser considerado semelhante metodologicamente aos questionários autopreenchidos ou realizados por telefone, diferenciando-se, apenas, na forma como são conduzidos (VIEIRA; CASTRO; JUNIOR SCHUCH, 2010). As questões do questionário consistiram em perguntas fechadas e semiestruturadas, que permitiram ao pesquisador ter dados mais uniformes a serem tratados.

\section{Instrumento da coleta de dados: elaboração do questionário}

A elaboração do questionário visou a aferir a percepção de estudantes surdos da UFSM sobre sua permanência em sala de aula, na relação aluno surdo-professor, aluno surdo-intérprete

\footnotetext{
${ }^{3}$ Protocolo CAAE 58219516.3.0000.5504.
} 
O que dizem os estudantes surdos da Universidade Federal de Santa Maria sobre a sua permanência...

de Libras e aluno surdo-aluno ouvinte, portanto, todas as perguntas se referiram à temática em questão.

A primeira versão do questionário foi enviada para dois juízes surdos (um mestre e um doutor) e oito juízes ouvintes (sete mestres e um doutor), para que fosse realizada a análise do conteúdo ${ }^{4}$. Após as reformulações pertinentes, foi aplicado um teste de clareza com quatro estudantes surdos de duas universidades diferentes e pertencentes a quatro cursos distintos, segundo as proposições de Fiorini e Manzini (2014). Após novos apontamentos, realizamos as modificações e, assim, o questionário ficou pronto para ser respondido pelos sujeitos participantes da pesquisa.

Ressaltamos que o meio eletrônico usado para disponibilizar o questionário foi o Google Forms ${ }^{\circledR}$ ou Formulário do Google ${ }^{\circledR}$, no qual é possível planejar eventos, criar pesquisas ou votações e preparar testes para alunos, bem como, coletar outras informações de forma simples e rápida por meio de formulários.

Nesse questionário, a primeira seção se constituía do aceite ou não em participar da pesquisa; na segunda seção foi disponibilizado o Termo de Consentimento Livre e Esclarecido para leitura e aceite das informações constantes; na terceira seção foram solicitadas informações pessoais dos sujeitos; nas seções seguintes, foram disponibilizadas as questões de 1 a 24 , com múltipla escolha em cada uma delas, e o participante só acessava a próxima seção após responder a seção anterior. Assim, conseguimos garantir 100\% das respostas para cada participante (APÊNDICE A).

\section{Sujeitos da pesquisa}

Os sujeitos convidados a responder o questionário da presente pesquisa foram 21 estudantes surdos da UFSM, todos regularmente matriculados na instituição. Porém, responderam efetivamente ao questionário 18 sujeitos, e os critérios de inclusão na pesquisa foram: a) estar cursando graduação na UFSM e b) declarar-se fluente em Libras.

A média de idade dos participantes foi de 25 anos, sendo 38,9\% do sexo feminino e $61,1 \%$ do sexo masculino, e os cursos que frequentavam na UFSM eram: Administração, Arquitetura e Urbanismo, Ciência da Computação, Educação Especial, Educação Física, Engenharia da Computação, Teatro, Medicina Veterinária, Pedagogia, Psicologia e Sistemas de Informação.

\section{Análise e tratamento dos dados}

Foram analisados 18 questionários dos 20 recebidos - dois foram eliminados por não atenderem aos critérios de inclusão da pesquisa. Após o recebimento das respostas pelos participantes, foi checado se as informações pessoais disponibilizadas pela UFSM condiziam com as respostas obtidas.

A análise dos dados se deu por meio da análise qualitativa - selecionando-se elementos que se associavam diretamente à problemática estudada, ou seja, adequando os métodos e as técnicas à natureza do problema investigado (LAKATOS; MARCONI, 1991) - e quantitativa, pois os dados numéricos coletados foram transformados em gráficos e, assim, analisados por

\footnotetext{
${ }^{4}$ Todos os juízes são profissionais da área de Educação Especial.
} 
meio da estatística descritiva. Desse modo, a pesquisa teve caráter misto. Esta é uma abordagem de investigação que

\begin{abstract}
Envolve suposições filosóficas, o uso de abordagens qualitativas e quantitativas e a mistura das duas abordagens em um estudo. Por isso, é mais do que uma simples coleta e análise dos dois tipos de dados; envolve também o uso das duas abordagens em conjunto, de modo que a força geral de um estudo seja maior do que a pesquisa qualitativa ou quantitativa isolada (CRESWELL; PLANO CLARK, 2007 apud CRESWELL, 2010, p. 27).
\end{abstract}

Ao analisar o material coletado, buscou-se realizar uma análise geral, percebendo pontos de encontro e semelhanças, pormenorizando-os, a fim de captar também, por consequência, as mínimas diferenças existentes (FREITAS, 2002).

A partir do estudo do material teórico, na etapa posterior à análise dos dados, realizou-se sua interpretação, focalizando aspectos descritivos, explicativos e de reflexão presentes nas respostas.

\title{
Resultados e Discussões
}

Como elencado anteriormente, as questões contidas no questionário tinham objetivos claros e concisos, concernentes ao problema de pesquisa inicialmente traçado. Para análise dos dados, dividimos as respostas em três eixos temáticos: a) relação do aluno surdo com o professor ouvinte; b) relação do aluno surdo com o intérprete de Libras e c) relação do aluno surdo com os colegas de sala ouvintes.

As três primeiras questões tinham por objetivo levantar informações da relação da UFSM com os alunos surdos matriculados em seus cursos de graduação. A primeira questão revelou que, quanto ao acesso à Universidade, o vestibular em Libras foi bom para $50 \%$ dos que responderam ao questionário; já para 33,3\%, o vestibular em Libras foi ótimo e para 16,7\% foi regular, nenhum aluno assinalou a opção ruim ou péssima.

Estudos apontam que: “[...] os vestibulares em Libras são eficazes, já que os surdos entendem o que se pede na sua língua" (ROCHA, 2015, p. 110). Além disso, advertem para a "[...] pertinência de o Enem, enquanto essas melhorias no Ensino Básico [escolas inclusivas com o devido preparo para receber os alunos surdos] não ocorrem, ser traduzido em Libras - no formato vídeo-gravado" (ROCHA, 2015, p.110). Nota-se que as provas em Libras agradam a maior parte dos surdos, viabilizando o acesso e a compreensão do que está expresso em língua portuguesa - língua esta que nem sempre é dominada por esse público. Acreditamos que a oferta da prova em Libras promova mais segurança aos surdos quanto à compreensão do conteúdo e expressão do seu saber, gerando menor preocupação com as questões de compreensão da língua - aspecto formal.

Outra questão que nos interessou foi entender o motivo da escolha, pelos alunos surdos, pela UFSM, e lhes foram apresentadas cinco opções. Observa-se o resultado no Gráfico 1. 
O que dizem os estudantes surdos da Universidade Federal de Santa Maria sobre a sua permanência...

Gráfico 1 - A escolha da UFSM

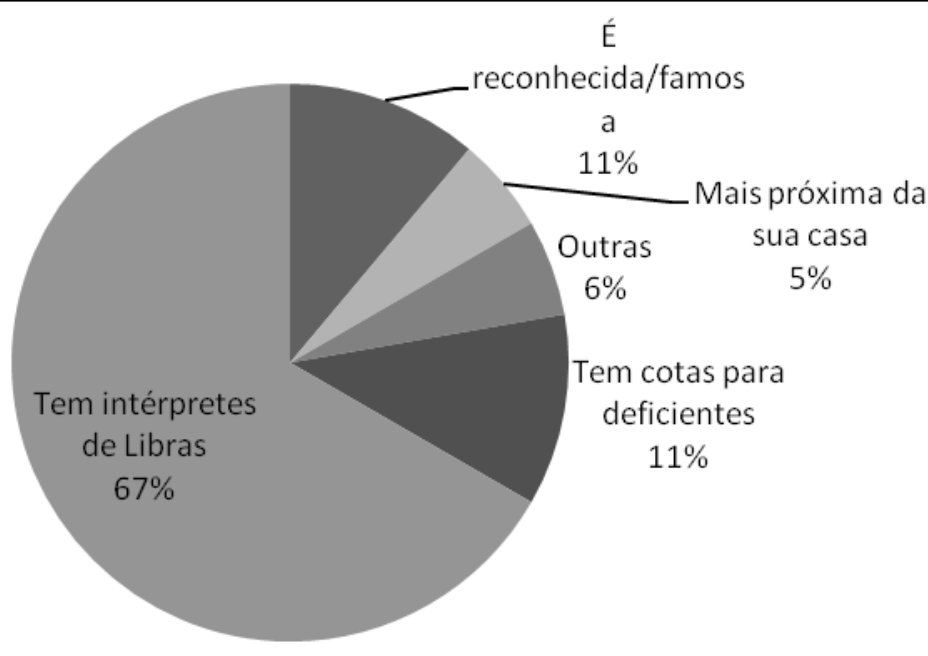

Fonte: Elaborado pelos autores.

Nota-se que o principal critério de escolha foi o fato de a universidade possuir intérpretes de Libras. Um dos alunos marcou a opção 'outras', porém não usou o campo delimitado para justificar sua escolha.

Vale ressaltar que, de acordo com o Decreto 5.626/05 (BRASIL, 2005), todas as universidades e escolas devem contar com a presença do intérprete de Libras, caso haja surdos matriculados. Entretanto, nem sempre essa é a realidade e muitos surdos ainda necessitam solicitar judicialmente o cumprimento de seus direitos.

Parece-nos que a escolha se dá não apenas pela presença do Tradutor e Intérprete de Língua de Sinais - TILS, mas pela presença de outros estudantes surdos na UFSM, fato que, além de propiciar o contato e a relação com seus pares, garante uma maior circulação da Libras e um ambiente mais acessível.

Buscamos também compreender a participação do núcleo de acessibilidade da UFSM, que vem ofertando condições de acessibilidade e permanência aos alunos e servidores na instituição e atende aos alunos público-alvo da educação especial, inclusive os surdos, na vida acadêmica desses estudantes. 
Gráfico 2 - O núcleo de acessibilidade e a permanência em sala de aula

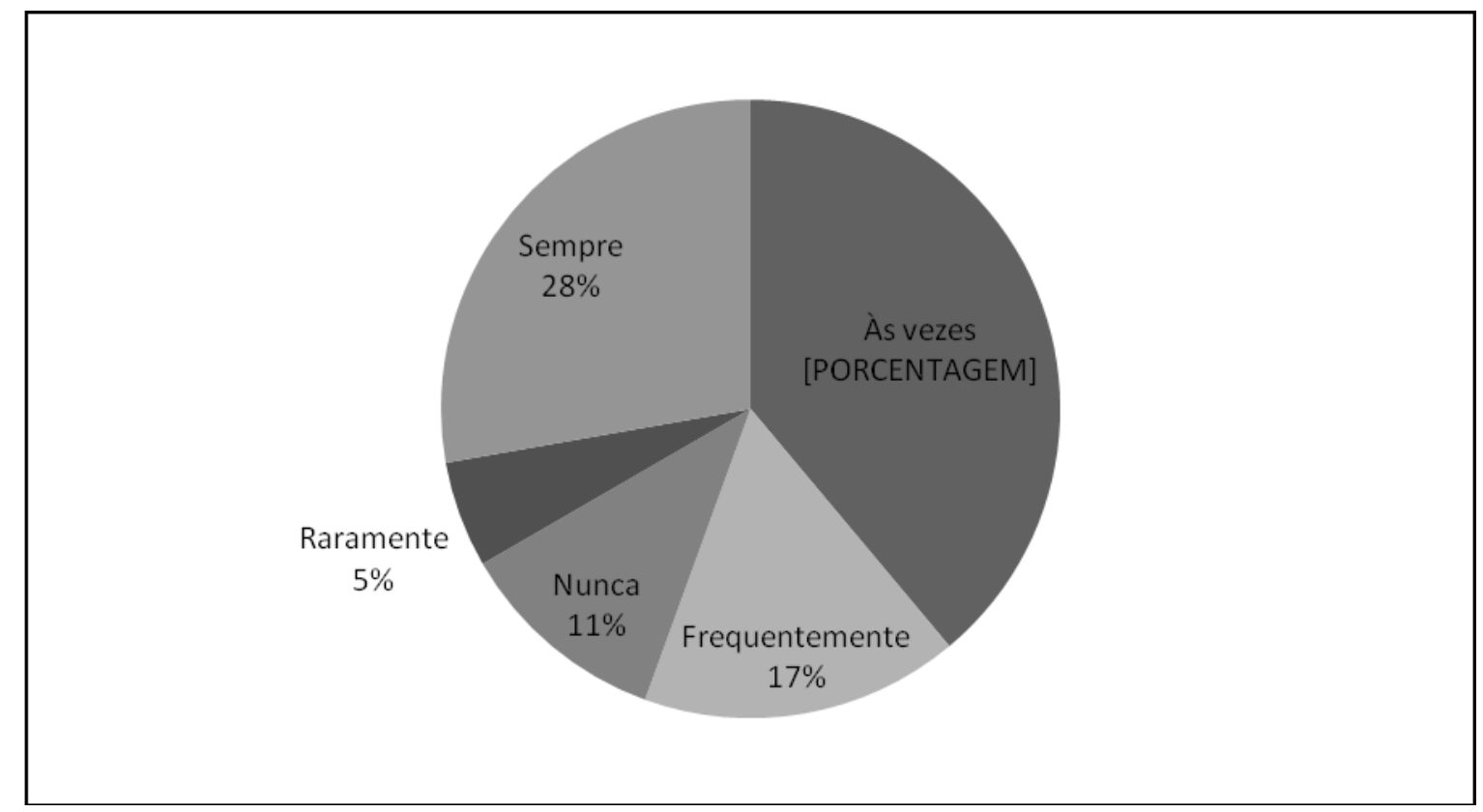

Fonte: Elaborado pelos autores.

Pelo exposto, 45\% dos surdos acreditam que o núcleo contribui frequentemente (17\%) ou sempre (28\%) para sua permanência em sala de aula; já a opção às vežes foi apontada por $39 \%$ dos participantes.

Na pesquisa de Ansay (2009), a autora identificou que para a permanência de estudantes surdos no ensino superior, faz-se necessário instituir: "[...] núcleos de apoio; acessibilidade na comunicação (intérpretes e o uso da leitura labial), a mediação no processo de ensino e aprendizagem feito pelos colegas e professores dos alunos surdos e recursos didáticopedagógicos adequados ao perfil dos alunos surdos" (p.113). Porém, ao analisar a permanência de alguns surdos incluídos nas Instituições de Ensino Superior - IES, constatou-se que há: falta de intérpretes, despreparo dos professores, preconceito e discriminação e falta ou uso inadequado do material didático pedagógico para esse alunado (ANSAY, 2009).

Apontamos aqui a necessidade de os núcleos de acessibilidade presentes nas universidades buscarem descobrir junto às pessoas com deficiências suas necessidades, pois, por vezes, o trabalho é mais genérico e não se centra nas reais demandas dos seus usuários. Os surdos demonstraram que nem sempre o núcleo tem contribuído de forma eficaz para sua permanência na Universidade.

\section{a) Relação do aluno surdo com o professor ouvinte}

Neste eixo, vamos analisar a relação dos alunos surdos com seus professores ouvintes. Para metade dos sujeitos, tal relação é regular (50\%); boa e ótima somaram 39\%; péssima ou ruim: $11 \%$. No que tange à forma de comunicação entre surdos e professores ouvintes, a mediação ocorre basicamente por meio do intérprete de Libras (61\%), de forma escrita (17\%), por meio da leitura orofacial $(11 \%)$ e outras formas $(11 \%)$. 
O que dizem os estudantes surdos da Universidade Federal de Santa Maria sobre a sua permanência...

Dois dos surdos marcaram a opção 'outras' (formas de comunicação), sendo que um deles descreveu que esta ocorre de forma "dupla": por meio do intérprete de Libras e pela escrita"; outro surdo respondeu que os professores ouvintes não sabem Libras e, por essa razão, não há comunicação.

Visto que a permanência dos estudantes surdos passa pelas questões linguísticas - sem uma língua acessível não há comunicação e, dificultando permanecer nesse espaço, esses estudantes parecem delegar ao intérprete a tarefa comunicativa e, com isso, os professores acabam por se eximir de aprender a língua dos seus alunos.

Destacamos que o docente não tem o dever de aprender a Libras fluentemente; há 11 anos, o Decreto 5.626/05 (BRASIL, 2005) indicou a obrigatoriedade da disciplina de Libras nos cursos de formação de professores e, por esta razão, muitos docentes não tiveram contato com essa língua em sua formação inicial. Deste modo, a inserção da disciplina na grade curricular dos cursos de licenciatura não garante ao professor fluência em Libras, visto que a carga horária mostra-se, na maioria dos casos, insuficiente, possibilitando apenas uma comunicação básica do professor com o aluno surdo (COSTA, 2015). Assim, a tarefa comunicativa depende do interesse e disponibilidade de cada docente que, muitas vezes, acaba delegando a tarefa ao intérprete de Libras.

Conforme apontamos anteriormente, os núcleos de acessibilidade poderiam, nessas situações, promover cursos à comunidade acadêmica, visando a melhorar a compreensão das necessidades dos alunos surdos - considerando o número de surdos incluídos na UFSM, essa atitude seria de fundamental relevância, visando a esclarecer aos docentes, funcionários e alunos, as especificidades da comunidade surda e suas necessidades no espaço educacional. Conforme expõe o Decreto 5.626/05, "Deve ser proporcionado aos professores acesso à literatura e informações sobre a especificidade linguística do aluno surdo" (BRASIL, 2005).

Indagamos aos estudantes surdos se os professores utilizam recursos visuais para melhor atendê-los durante as aulas, haja vista esses sujeitos serem mais bem contemplados quando amparados por tais recursos didáticos, que visam fundamentalmente a apoiar sua educação (BRASIL, 2005).

Foi possível perceber, pelas respostas dos participantes, que grande parte dos professores faz uso de recursos visuais em suas aulas: 55\%. Porém, há também uma parcela significativa de professores que não o utilizam: $17 \%$, o que certamente prejudica sua permanência na universidade e vai de encontro ao que está previsto pelo Decreto 5.626/2005, que esclarece sobre a disponibilização de "equipamentos, acesso às novas tecnologias de informação e comunicação" (BRASIL, 2005).

Concernente à disponibilização de tempo extra pelos professores para os alunos surdos durante a avaliação, apenas um dos participantes alegou que todos os seus professores disponibilizam tempo extra nas avaliações. No entanto, $50 \%$ dos alunos relataram que apenas a metade dos seus professores o disponibiliza; $17 \%$ responderam que a maioria o faz e $28 \%$ que nenbum dos professores disponibiliza tempo adicional nas avaliações. Esse fato vai de encontro ao Decreto 3.298/1999 (BRASIL, 1999), que consolidou as normas de proteção às pessoas com deficiência, assim evidenciando que:

\footnotetext{
${ }^{5}$ No questionário, não havia a possibilidade de marcar duas alternativas simultaneamente, o que o fez descrever tal alternativa. Sugerimos que, em caso de replicação do questionário em outras pesquisas, essa possibilidade seja contemplada.
} 
As instituições de ensino superior deverão oferecer adaptações de provas e os apoios necessários, previamente solicitados pelo aluno portador de deficiência ${ }^{6}$, inclusive tempo adicional para realização das provas, conforme as características da deficiência (BRASIL, 1999).

A correção de provas foi outro ponto discutido, haja vista o Decreto 5.626/2005 preconizar que as instituições devem "adotar mecanismos de avaliação coerentes com aprendizado de segunda língua, na correção das provas escritas, valorizando o aspecto semântico e reconhecendo a singularidade linguística manifestada no aspecto formal da Língua Portuguesa" (BRASIL, 2005). No entanto, é evidente nas respostas apresentadas pelos sujeitos, que a maioria dos professores desconhece tal legislação: apenas dois (11\%) participantes responderam que todos os seus professores realizam correção diferenciada de suas avaliações; nenbum dos professores realizou tal avaliação correspondeu a $33 \%$ das respostas dos estudantes surdos, e $28 \%$ dos participantes responderam que metade dos seus professores realizam avaliação diferenciada.

Nesse sentido, pelas respostas dos surdos ao questionário, percebe-se que ainda não se propõe uma formação continuada aos docentes, visando a promover um maior contato com as questões da surdez; o conhecimento certamente poderia trazer mudanças para a realidade desta Universidade. Estudos apontam que com a inserção de Libras nos currículos de formação de professores, há uma contribuição "[...] para a mudança de concepções acerca da surdez, da pessoa surda e da língua brasileira de sinais" (NASCIMENTO; SOFIATO, 2016, p. 359) e, ainda "[...] de forma significativa para que os alunos adquiram conhecimentos relativos à área de forma basilar e efetiva, com vistas a uma possível continuidade dos estudos posteriores" (idem, p. 361).

Questionados sobre o envio de materiais com antecedência pelos professores ao intérprete de Libras, para que este tenha acesso ao conteúdo e possa realizar uma interpretação mais segura, verificou-se que houve respostas bem distintas, prevalecendo a de que todos ou maioria enviam o material $(50 \%)$ com antecedência aos estudantes ou intérpretes de Libras. Essa atitude colabora para uma melhor atuação dos intérpretes em sala de aula. Pouco mais da metade dos professores, de acordo com os sujeitos da pesquisa, também enviam material, o que somou $28 \%$. A informação de que a minoria ou nenbum professor encaminha com antecedência foi prestada por $22 \%$ dos entrevistados. Sobre essa questão, pode-se afirmar que:

\footnotetext{
Embora o domínio das línguas seja inerente ao trabalho do intérprete, sua formação/atuação tem caráter generalista, então, em tais situações, o profissional, a fim de garantir uma boa atuação, deve ter acesso anterior às temáticas que serão abordadas (quer em uma palestra, quer com relação à sala de aula). Por se tratar de uma profissão relativamente nova, apenas recentemente organizadores de eventos têm se comprometido em oferecer acesso aos conteúdos, o que é menos comum para professores. Não estamos afirmando que isso, por si só, garanta o bom desempenho do intérprete, mas saber o assunto que será abordado com certa antecedência pode dar mais segurança ao profissional no momento de sua atuação, uma vez que possibilita sua preparação prévia e algum estudo (SANTOS, 2014, p. 65).
}

Sobre o fator disponibilidade pelos professores ouvintes em atender os estudantes surdos, tivemos respostas bastante distintas, conforme disposto no gráfico seguinte:

${ }^{6}$ Uso do termo no original. Atualmente usado como pessoa com deficiência.

Práxis Educativa, Ponta Grossa, v. 12, n. 3, p. 826-847, set./dez. 2017 Disponível em: <http://www.revistas2.uepg.br/index.php/praxiseducativa > 
O que dizem os estudantes surdos da Universidade Federal de Santa Maria sobre a sua permanência...

Gráfico 3 - Disponibilidade do professor em horários alternativos para atendimento às dúvidas

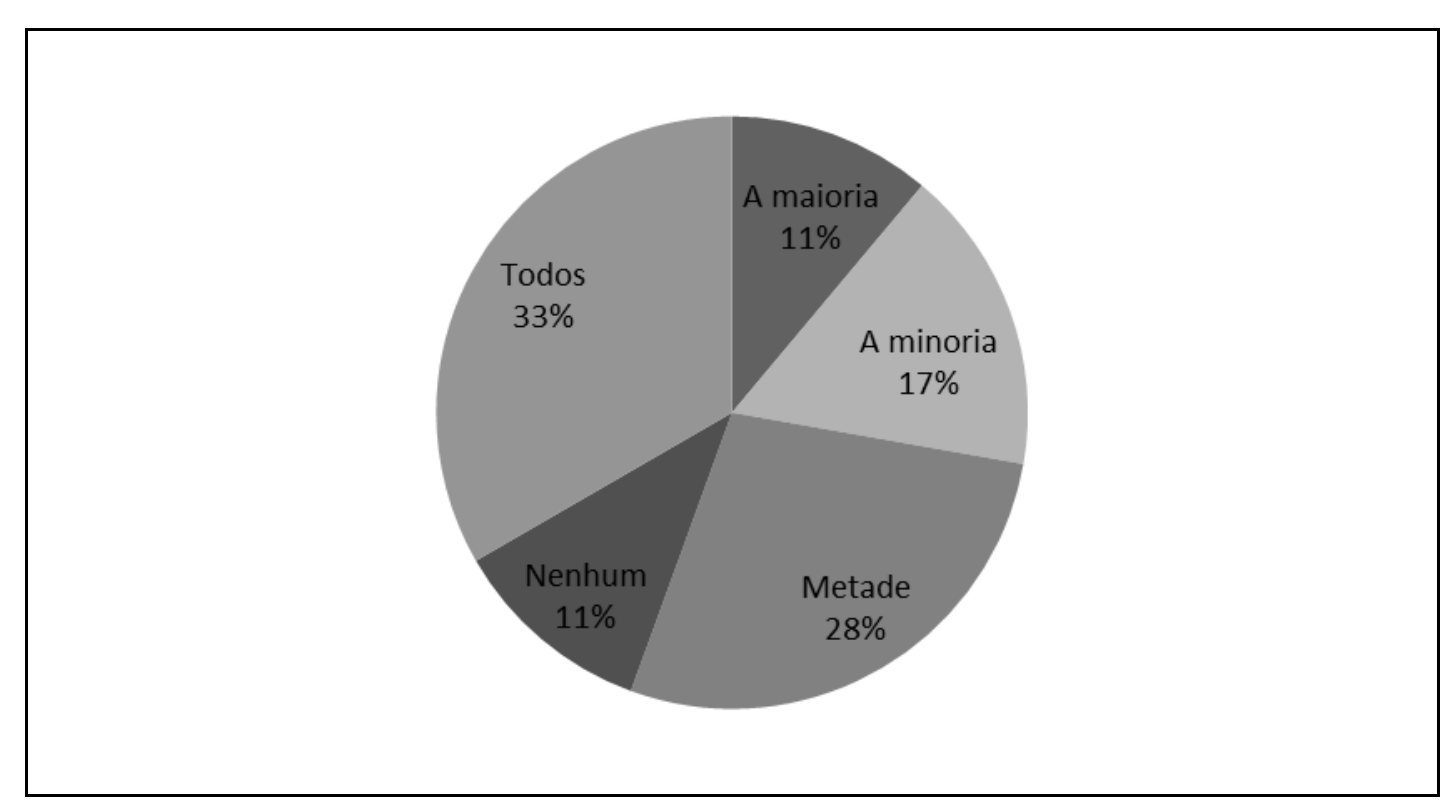

Fonte: Elaborado pelos autores.

Mesmo com as distinções entre as respostas, é notório que muitos professores não têm disponibilidade para atender aos surdos fora da sala de aula, ou seja, as questões e as dúvidas que surgem após as aulas dificilmente serão sanadas: $11 \%$ dos surdos relatam que nenhum dos seus professores os atende em horário distinto à aula.

\section{b) Relação do aluno surdo com o intérprete de Libras}

Sobre a relação dos estudantes surdos com os intérpretes de Libras, grande parte destes relata que esta ocorre de forma ótima e boa $(95 \%)$ e para apenas um estudante tal relação é regular, demonstrando um entrosamento positivo nas relações, o que pode influenciar de maneira satisfatória na tradução e interpretação dos conteúdos em sala de aula pelos intérpretes de Libras da UFSM e, consequentemente, no aprendizado desses estudantes, pois partilham de uma mesma língua no espaço educacional (GURGEL, 2004).

Sobre essa parceria entre TILS e surdos, Santos (2014) esclarece que "É nesse contexto que o intérprete precisa estabelecer parceria com o professor, e também com o aluno, sem que tais relações demarquem uma postura favorável a um ou outro" (p. 73). Nesse sentido, alguns autores comungam da ideia de que, embora haja muitos outros elementos que influenciam esse complexo ato, a parceria sendo favorável, o aprendizado e a interpretação também serão eficazes (SANTOS, 2014; ROCHA, 2015).

Com relação à fluência em Libras dos intérpretes para o desempenho de suas atividades em sala de aula, as repostas variaram bastante. No entanto, para grande parte dos surdos (55\%), todos os TILS têm fluência ou a maioria destes; para $28 \%$, metade dos TILS são fluentes e $17 \%$ responderam que nenbum ou a minoria tem fluência em Libras.

Nesse ponto, vale destacar que a UFSM tinha grande quantitativo de surdos e, por essa razão, o quadro de intérpretes de Libras era insuficiente para atender a demanda da universidade ${ }^{7}$,

\footnotetext{
${ }^{7}$ Realidade vivenciada em 2015.
} 
que optou por contratar alguns bolsistas para atuar como intérpretes, cujo conhecimento linguístico, muitas vezes, era restrito e limitado. Essa medida, entretanto, mostrou-se inevitável, dada a necessidade dos surdos em ser assistidos por alguém com conhecimento em Libras na sala de aula. Tal situação foi modificada com a contratação de mais TILS efetivos e a diminuição da demanda de surdos na universidade, atual realidade da UFMS (2016).

Ainda sobre o intérprete de Libras e a relação dos surdos com estes, auscultou-se sobre a permanência ou não dos TILS durante as avaliações em sala de aula e houve, nessa resposta, certa homogeneidade, pois $95 \%$ dos estudantes surdos responderam que o TILS fica em sala com eles durante a avaliação. Apenas um deles respondeu que o profissional fica em alguns casos específicos e, no campo destinado à explanação da resposta, afirma que a permanência ocorre até ele entender o que está posto em Português e, depois, não há mais necessidade.

A disponibilidade dos intérpretes de Libras para assessoramento dos surdos após as aulas foi outro ponto levantado e as repostas divergiram nas colações pelos estudantes, conforme se vê no gráfico seguinte.

Gráfico 4 - Disponibilidade dos intérpretes em horários alternativos para atendimento às dúvidas

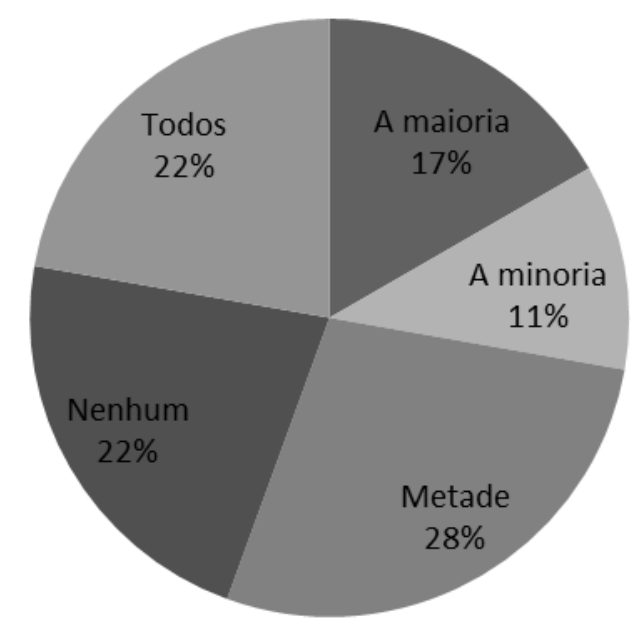

Fonte: Elaborado pelos autores.

A partir de tais respostas, buscamos entender o porquê de tais divergências. Como é sabido, o número de surdos na instituição é grande (comparado a outras realidades brasileiras), portanto, a demanda de atendimento é alta, o que faz com que os intérpretes não tenham muito tempo disponível para atendimento dos estudantes em horário extra. Segundo 33\% deles, a minoria ou nenbum destes podem atendê-los.

Embora o intérprete não seja responsável diretamente pelo ensino ao aluno surdo, sua participação nas práticas educacionais é inevitável. Diferentemente de um intérprete de conferências ou da área da saúde, o Intérprete educacional (IE) ${ }^{8}$ tem relação diária e muito

\footnotetext{
${ }^{8}$ O termo intérprete educacional, utilizado de forma muito adequada por Lacerda (2009), designa o profissional que, para além dos processos tradutórios, envolve-se nas práticas pedagógicas/educacionais. A autora afirma que, devido a esse envolvimento, o profissional acaba por constituir habilidades bastante específicas e também desenvolve conhecimentos acerca de aspectos educacionais, visando à aquisição de conhecimentos pelo aluno surdo.
} 
O que dizem os estudantes surdos da Universidade Federal de Santa Maria sobre a sua permanência...

próxima do aluno surdo e de professores, o que traz uma marca identitária diferente dos profissionais dos demais contextos de atuação.

Considerando a efemeridade e rapidez dos diálogos/conceitos que circulam em sala de aula, seria de grande relevância disponibilizar um tempo extra para atendimento aos alunos. Não se trata de substituir a função do professor, mas retomar aspectos que tenham ficado pouco claros e sanar dúvidas em outro momento, com alguém que partilhe da mesma língua. Concordamos com Santos (2014, p. 162) quando afirma que "O IE necessita maior reflexão sobre suas ações, sobre seus papéis, de forma a se assumir e consolidar, também, como um educador; a atuação em sala de aula exige uma postura mais criativa, mais autônoma e menos 'presa' às questões apenas de interpretação".

No que concerne ao auxílio na tradução de materiais da língua portuguesa para a língua de sinais, grande parte dos TILS auxilia os surdos: $61 \%$ - o que colabora para a permanência destes na universidade, já que alguns precisam de tal tradução a fim de compreender o que está posto em língua portuguesa.

As adequações das aulas para melhor atendimento aos estudantes surdos, tais como recusos visuais, aceitação do Português como segunda língua e outros, em muito contribui para a sua permanência. Os participantes da pesquisa esclarecem que grande parte $(56 \%)$ dos seus intérpretes realizam interferências na aula a fim de esclarecer aos professores a forma mais perspicaz na sua inclusão e outra parte disse que metade (33\%) ou nenhum (11\%) faz esse diálogo com os professores.

Nesse sentido, Lacerda (2008) esclarece que:

O professor é responsável pelo planejamento das aulas, por decidir quais são os conteúdos adequados, pelo desenvolvimento e pela avaliação dos alunos, todavia o IE [intérprete educacional] conhece bem os alunos surdos e a surdez e pode colaborar com o professor sugerindo atividades, indicando processos que foram mais complicados, trabalhando em parceria, visando a uma inclusão mais harmoniosa dos alunos surdos (LACERDA, 2008, p. 17).

Do ponto de vista dos alunos surdos, os TILS têm um bom relacionamento com seus professores: $78 \%$, e apenas quatro alunos responderam que a minoria ou metade tem um bom relacionamento com seus professores. Nessa perspectiva, fica evidente que, se o TILS não se relaciona bem com o professor, certamente este não terá respaldo para sugerir adequações curriculares, o que possivelmente será prejudicial à permanência dos surdos na universidade.

O relacionamento harmonioso entre TILS e professor é fundamental, assim, "cabe ao professor adquirir uma postura favorável frente a esse profissional, pois a parceria entre IE e professor é crucial para que os conhecimentos sejam apropriados pelo aluno surdo" (SANTOS, 2014, p. 30). Desse modo, fica evidente que a parceria entre ambos os profissionais é que fará com que de fato haja um aprendizado significativo para o aluno surdo.

\section{c) Relação do aluno surdo com os colegas da sala}

Sobre a relação dos alunos surdos com os colegas ouvintes, aqueles responderam que ocorre de maneira boa (56\% dos participantes) e, para $28 \%$, ela é regular. Somente um aluno respondeu que é ótima; já ruim e péssima somaram $10 \%$.

Pode-se verificar, pela resposta à questão 20, que boa parte dos alunos tem um relacionamento favorável com seus colegas ouvintes, não o ideal, pois somente um surdo 
respondeu que tal relacionamento é ótimo. Isto é esperado, considerando que as salas de aulas são cada vez mais heterogêneas em sua constituição, e a língua de sinais não é dominada pela maioria ouvinte.

Concernente ao aprendizado da Libras pelos colegas ouvintes, poucos são os que sabem tal língua. Apenas um surdo assinalou que a maioria dos colegas de sua sala sabem Libras e, possivelmente, seja a mesma pessoa que assinalou que sua relação com os colegas da sala é ótima, no entanto, nenbum surdo marcou a opção "todos os alunos sabem Libras"; 33\% disseram que metade da sala sabe Libras. A minoria e nenbum somaram 61\%, o que é alarmante, pensando que todo o processo de acesso do estudante surdo perpassa pelo uso da língua de sinais.

Fica evidente que o não aprendizado da língua de sinais pelos colegas ouvintes interfere de forma negativa na sua relação e permanência em sala de aula, e as duas perguntas anteriores comprovaram tal situação. Na pesquisa de Lacerda (2006), com professores, alunos e intérpretes de Libras, ela evidenciou que muitas vezes o aluno surdo "é um estrangeiro que tem acesso aos conhecimentos de um modo diverso dos demais e se mantém isolado do grupo (ainda que existam contatos e um relacionamento amigável” (p. 77).

A participação dos alunos surdos nos grupos ou apresentações de trabalho em sala de aula foi outro questionamento que elencamos, pois em muito retrata a realidade da permanência desses sujeitos na universidade. Assim, foi possível verificar que a maioria dos alunos ou todos são acolhedores quanto à participação dos estudantes surdos nos grupos ou trabalhos em sala de aula, no entanto, $45 \%$ dos surdos afirmam que a minoria, metade e nenbum dos alunos ouvintes os recebe como deveria, o que é retrato de uma inclusão que os exclui, ao mesmo tempo em que se propõe a incluir. Assim, ressalta Lacerda (2006):

A inclusão apresenta-se como uma proposta adequada para a comunidade escolar, que se mostra disposta ao contato com as diferenças, porém não necessariamente satisfatória para aqueles que, tendo necessidades especiais, necessitam de uma série de condições que, na maioria dos casos, não têm sido propiciadas pela escola (p. 166).

Já se é sabido que a colaboração entre colegas em sala de aula é algo rotineiro e isso contribuiu para a socialização e colaboração mútua, no entanto, todo o processo é mediado pela língua. Cinquenta por cento dos surdos participantes da pesquisa relataram que tal colaboração ocorre para uma minoria, nenhum ou com metade de seus colegas.

Ainda sobre a socialização, reunir-se com os colegas para estudar é algo bastante rotineiro em salas de ouvintes, no entanto, pelas repostas dos participantes da pesquisa, isso parece ocorrer de forma pouco frequente, conforme demonstrado no gráfico a seguir. 
O que dizem os estudantes surdos da Universidade Federal de Santa Maria sobre a sua permanência...

Gráfico 5 - Frequência de reuniões de estudo com colegas de sala.

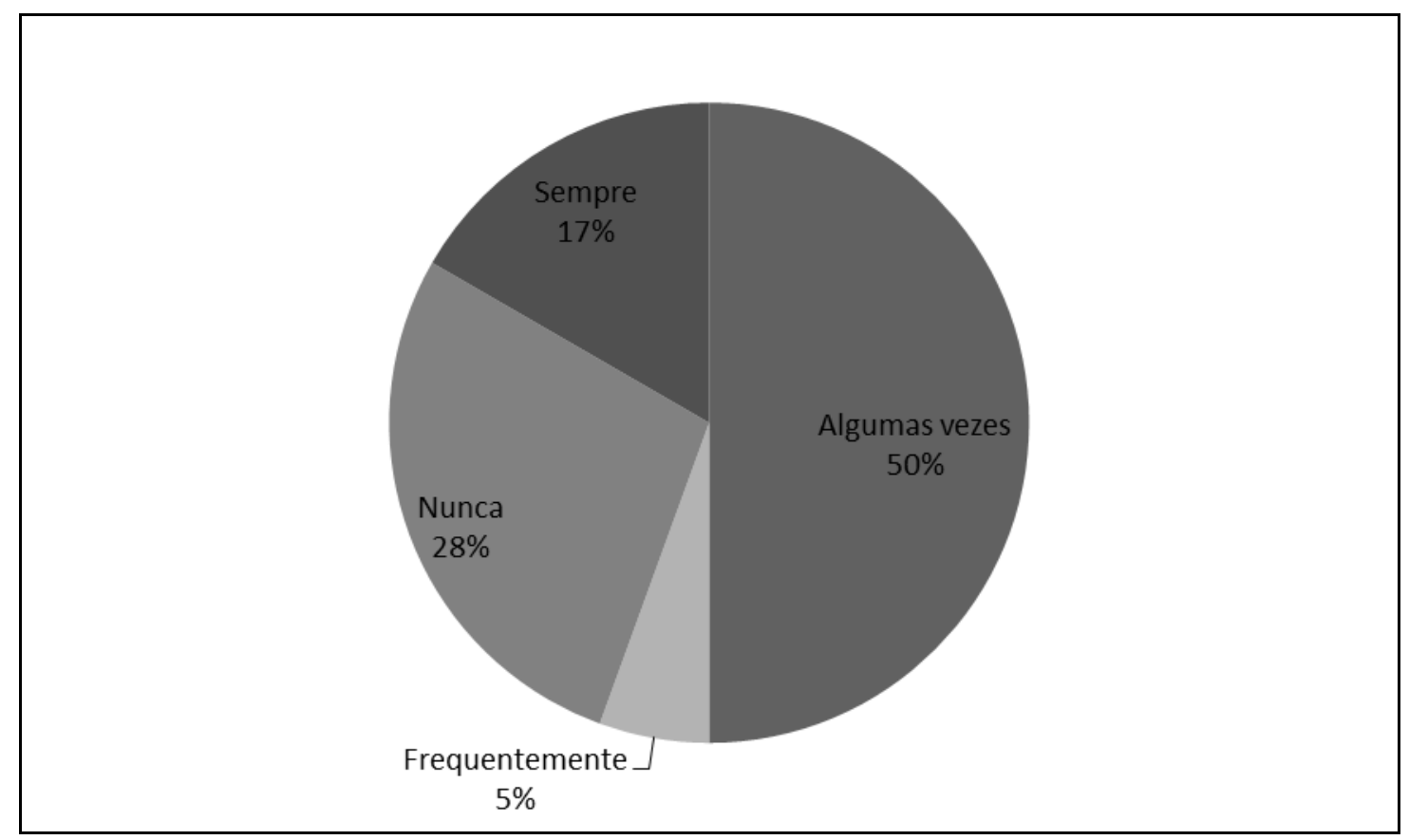

Fonte: Elaborado pelos autores.

Tal reflexo de poucos 'compartilhamentos' em sala de aula impacta diretamente na permanência dos sujeitos surdos na Universidade, pois, por vezes, sentem-se pouco acolhidos. Pode-se questionar se é isso que os faz isolar-se, já que não partilham de uma língua comum ao grupo social em que estão inseridos, ou seriam os demais que os isolam por não entenderem sua língua? (GOES, 1996).

\section{Considerações Finais}

Pelas respostas dos participantes, fica evidente que, apesar de a UFSM ter um número notável de surdos e diferenciar-se quanto ao ingresso destes à universidade (vestibular videogravado em Libras - até 2015 , e cota - 5\% das vagas destinadas às pessoas com deficiência), a permanência ainda é algo a ser discutido, pois o aluno surdo tem, por vezes, sido rechaçado por políticas pouco sensíveis quanto à sua diferença linguística.

A relação do aluno surdo com seus professores, apesar de harmoniosa para a maioria, é negada pela falta de interesse destes no aprendizado da língua de sinais, na falta de compreensão destes quanto ao uso de recursos visuais e à disponibilização de tempo extra e à correção diferenciada dos aspectos semânticos dos alunos surdos nas avaliações escritas.

A relação do estudante surdo com o intérprete também tem ocorrido de maneira bastante satisfatória em sala de aula, no entanto, há que se considerar que a universidade tem oferecido poucos subsídios a esses estudantes quanto à disponibilização e horários desses profissionais para seu atendimento fora da sala de aula.

Aparentemente, o relacionamento entre alunos surdos e ouvintes é amigável e positivo; todavia é notório que se trata de relacionamentos superficiais, a partir do questionamento quanto às trocas em sala de aula e fora desta - o que, de acordo com as respostas, parece ocorrer com pouca frequência. 
Assim, concluímos que, apesar de o acesso à UFSM ser diferenciado e haver todo um investimento para a "captura de surdos", a permanência assemelha-se a outras realidades brasileiras e é pouco acolhedora com relação à sua diferença linguística.

Os núcleos de acessibilidade carecem de mais proximidade à realidade desses estudantes, a fim de reconhecer as necessidades de permanência desses alunos no espaço da Universidade. A inserção de intérpretes de Libras foi apenas o primeiro passo nessa direção, mas ainda há muito a se fazer com relação à adaptação de materiais, formação continuada ao docente, reflexões acerca da carga horária dos intérpretes (a fim de que possam se dedicar ao estudo e melhor preparação para atuação), entre outros aspectos que podem facilitar e garantir a permanência mais apropriada do aluno surdo na Universidade.

Há muito que investigar sobre essa temática. A pesquisa ora sintetizada é apenas o início de um longo trabalho investigativo, que não deve se esgotar por aqui. Assim, desejamos que futuras pesquisas sejam realizadas sobre a temática apresentada, e que os resultados descritos pelos surdos sejam considerados pelas universidades na elaboração de políticas de permanência mais inclusivas.

\section{Referências}

ANSAY, N. N. A Trajetória Escolar de Alunos Surdos e a sua Relação com a Inclusão no Ensino Superior. 2009. 133 f. Dissertação (Mestrado em Educação) - Universidade Federal do Paraná, Curitiba, 2009.

BISOL, C. A. et al. Estudantes surdos no ensino superior: reflexões sobre a inclusão. Cadernos de Pesquisa, São Paulo, v. 40, n. 139, p. 147-172, jan./abr. 2010. DOI: 10.1590/S010015742010000100008.

BRASIL. Ministério da Educação. Decreto no 3.298, de 20 de dezembro de 1999. Diário Oficial da União, Brasília, DF, 21 dez. 1999. Seção 1, p. 10. Disponível em: <http://portal.mec.gov.br/arquivos/pdf/decreto3298.pdf>. Acesso em: 07 ago. 2014.

BRASIL. Ministério da Educação. Decreto no 3.284, de 7 de novembro de 2003. Diário Oficial da União, Brasília, DF, 11 nov. 2003. Seção 1, p. 12. Disponível em: <http://portal.mec.gov.br/seesp/arquivos/pdf/port3284.pdf>. Acesso em: 03 ago. 2014.

BRASIL. Decreto $\mathrm{n}^{\mathrm{0}}$ 5.626, de 22 de dezembro de 2005. Diário Oficial da União, Poder Executivo, Brasília, DF, 23 dez. 2005. Seção I, p. 28. Disponível em: <http://www.planalto. gov.br/ccivil_03/_ato2004-2006/2005/decreto/d5626.htm>. Acesso em: 05 ago. 2014.

BRASIL. Recomendação ${ }^{\circ}$ 001. Brasília: Secretaria Especial dos Direitos Humanos/ Conselho Nacional dos Direitos da Pessoa Portadora de Deficiência, 2010.

BRASIL. Ministério da Educação. Referenciais de acessibilidade na Educação Superior e a avaliação in loco do Sistema Nacional de Avaliação do Ensino Superior (SINAES). Ministério da Educação/Instituto Nacional de Estudos e Pesquisas Educacionais Anísio Teixeira (Inep)/Diretoria de Avaliação da Educação Superior/Coordenação-Geral de Avaliação de Cursos de Graduação e IES. Jul. 2013. Disponível em: <http://www.ampesc.org.br/_arquivos/download/1382550379.pdf>. Acesso em: 27 jul. 2014. 
O que dizem os estudantes surdos da Universidade Federal de Santa Maria sobre a sua permanência...

CASTRO, S. F. Ingresso e permanência de alunos com deficiência em universidades públicas brasileiras. 2011. 278 f. Tese (Doutorado em Educação do Indivíduo Especial) Universidade Federal de São Carlos, São Carlos, 2011.

COSTA, O. S. Implementação da disciplina de Libras nas licenciaturas em município do interior de São Paulo. 2015. 90 f. Dissertação (Mestrado em Educação Especial) - Universidade Federal de São Carlos, São Carlos, 2015.

CRESWELL, J. W. Projeto de pesquisa: métodos qualitativo, quantitativo e misto. Porto Alegre: Artmed, 2010.

DAROQUE, S. C.; PADILHA, A. M. L. Alunos Surdos no Ensino Superior: uma discussão necessária. Comunicações, Piracicaba, v. 19, p. 23-32, 2012.

FIORINI, M. L. S.; MANZINI, E.J. Elaboração de questionário para aferir concepções sobre inclusão de aluno com deficiência em aulas de educação física. Revista da Sobama, Marília, v. 15, n. 1, p. 21-30, 2014.

FREITAS, M. T. de A. A abordagem sócio-histórica como orientadora da pesquisa qualitativa. Cadernos de Pesquisa, São Paulo, n. 116, p. 21-39, jul. 2002. DOI: 10.1590/s010015742002000200002

GIL, A. C. Como elaborar projetos de pesquisa. 5. ed. São Paulo: Atlas, 2008.

GÓES, M.C.R. Linguagem, surdez e educação. Campinas: Autores Associados, 1996.

GOULARTE, R. B. Acesso e permanência no ensino superior: estratégias de governamento da conduta de alunos surdos inclú́dos. 2014. 107 f. Dissertação (Mestrado em Educação) Universidade Federal de Santa Maria, Santa Maria, 2014.

GURGEL, T. M. A. O papel do instrutor surdo na promoção da vivência da língua de sinais por crianças surdas. 2004. 90f. Dissertação (Mestrado em Educação) - Universidade Metodista de Piracicaba, Piracicaba, 2004.

JUNIOR, E. R. da C. A modelação de uma Política Cooperativa na Formação de Estudantes Surdos no Ensino Superior. 2015. 149 f. Dissertação (Mestrado em Educação) Universidade Federal do Espirito Santo, Vitória, 2015.

LACERDA, C. B. F. de. A inclusão escolar de alunos surdos: o que dizem alunos, professores e intérpretes sobre esta experiência. Cadernos Cedes, Campinas, v. 26, n. 69, p. 163-184, maio/ago. 2006. DOI: 10.1590/s0101-32622006000200004

LACERDA, C. B. F. de. O Intérprete de Língua Brasileira de Sinais: investigando aspectos de sua atuação na educação infantil e no ensino fundamental. 2008. Disponível em: <http://www.ppgees.ufscar.br/LACERDA \%202008\%20Interprete\%20de\%20Libras.pdf.>.

Acesso em: 08 nov. 2016.

LACERDA, C. B. F. de. Intérprete de Libras: em atuação na educação infantil e no ensino fundamental. Porto Alegre: Mediação/FAPESP, 2009. 
LAKATOS, E.M.; MARCONI. M. A. Fundamentos de Metodologia Científica. São Paulo: Atlas, 1991.

NASCIMENTO, L. C. R.; SOFIATO, C. G. A disciplina de língua brasileira de sinais no ensino superior: compartilhando experiências. ETD - Educação Temática Digital, Campinas, SP, v. 18, n. 2, p. 352, abr./jun. 2016. DOI: 10.20396/etd.v18i2.8639505

ROCHA, L. R. M. O que dizem surdos e gestores sobre vestibulares em Libras para ingresso em universidades federais. 2015. 125 f. Dissertação (Mestrado em Educação Especial) - Universidade Federal de São Carlos, São Carlos, 2015.

SANTOS, L. F. O fazer do intérprete educacional: práticas, estratégias e criações. 2014. 203 f. Tese (Doutorado em Educação do Indivíduo Especial) - Universidade Federal de São Carlos, São Carlos, 2014.

SILVA, A. M.; CYMROT, R.; D'ANTINO, M. E. F. Demandas de docentes do ensino superior para a formação de alunos com deficiência. Revista Brasileira de Estudos Pedagógicos, Brasília, v. 93, n. 235, p. 667-697, set./dez. 2012. DOI: 10.1590/s2176-66812012000400008

UNIVERSIDADE FEDERAL DE SANTA MARIA (UFSM). Edital do Vestibular de 2014. Santa Maria, 2014.2 Disponível em: <http://www.coperves.ufsm.br/concursos/vestibular_2014/>. Acesso em: 07 mar. 2015.

VIEIRA, H. C.; CATRO A. E.; JUNIOR SCHUCH, V. F. O uso de questionários via e-mail em pesquisas acadêmicas sob a ótica dos respondentes. In: SEMEAD- SEMINÁRIOS EM ADMINISTRAÇÃO, 13., 2010. Anais... São Paulo- SP: USP, 2010. P. 1-13. Disponível em: $<$ http://www.ead.fea.usp.br/semead/13semead/resultado/trabalhosPDF/612.pdf $>$. Acesso em: 07 mar. 2015. 
O que dizem os estudantes surdos da Universidade Federal de Santa Maria sobre a sua permanência...

APÊNDICE A - Questionário com os estudantes surdos da UFSM.

Nome:

Idade:

Curso:

Ano/Semestre do curso:

Sexo: ( ) Masculino ( ) Feminino

1. Avalie o vestibular em Libras no seu ingresso à UFSM.

( ) Péssimo

( ) Ruim

( ) Regular

( ) Bom

( ) Ótimo

2. Por que você escolheu a UFSM para estudar?

() Tem intérprete de Libras

() É reconhecida

() Tem cotas para deficientes

() Mais próxima da sua casa

() Outras

3. O núcleo de acessibilidade da UFSM contribui para a sua permanência em sala de aula?

( ) Sempre

( ) Frequentemente

( ) Às vezes

( ) Raramente

( ) Nunca

4. Como é a sua relação com seus professores ouvintes.
( ) Péssima
( ) Ruim
( ) Regular
( ) Boa
( ) Ótima

5. Seus professores se interessam em aprender Libras?
( ) Todos
( ) A maioria
( ) Metade
( ) A minoria
( ) Nenhum

6. Qual a principal forma de comunicação com seus professores ouvintes?

( ) Por meio do Intérprete de Libras

( ) de forma oral e leitura orofacial

( ) de forma escrita

( ) Outra: - especifique 
7. Seus professores usam recursos visuais (data-show, materiais concretos, imagens e outros) para sua melhor compreensão nas aulas?
( ) Todos
( ) A maioria
( ) Metade
( ) A minoria
( ) Nenhum

8. Seus professores disponibilizam tempo extra a você nas provas, caso precise?
( ) Todos
( ) A maioria
( ) Metade
( ) A minoria
( ) Nenhum

9. Seus professores fazem correção diferenciada da sua forma de escrita do português (como segunda língua) ao corrigir as suas avaliações e trabalhos?
( ) Todos
( ) A maioria
( ) Metade
( ) A minoria
( ) Nenhum

10.Seus professores retomam o conteúdo da aula para você quando o intérprete de Libras precisa se ausentar?
( ) Todos
( ) A maioria
( ) Metade
( ) A minoria
( ) Nenhum

11.Seus professores disponibilizam a você e/ou o intérprete de Libras, com antecedência, o material que irá usar nas aulas?

( ) Todos

( ) A maioria

( ) Metade

( ) A minoria

( ) Nenhum

12.Seus professores têm disponibilidade para atendê-lo em outro horário, caso tenha dúvidas do conteúdo exposto em sala de aula?
( ) Todos
( ) A maioria
( ) Metade
( ) A minoria
( ) Nenhum

13.Como é a sua relação com os intérpretes de Libras.
( ) Péssima
( ) Ruim 
O que dizem os estudantes surdos da Universidade Federal de Santa Maria sobre a sua permanência...
( ) Regular
( ) Boa
( ) Ótima

14.Seus intérpretes são fluentes em Libras para o trabalho em sala de aula?

( ) Todos

( ) A maioria

( ) Metade

( ) A minoria

( ) Nenhum

15.Nas avaliações (provas) os intérpretes ficam na sala de aula com você?

( ) $\operatorname{Sim}$

( ) Não há necessidade

( ) Os professores não deixam

( ) Em alguns casos: quais?

16.Os intérpretes têm disponibilidade para atendê-lo (tirar dúvidas e outras atividades) em horário extra às aulas?
( ) Todos
( ) A maioria
( ) Metade
( ) A minoria
( ) Nenhum

17.Na leitura dos textos escritos em português, seus intérpretes de Libras te auxiliam na tradução do material ou compreensão destes?
( ) Todos
( ) A maioria
( ) Metade
( ) A minoria
( ) Nenhum

18.Seus intérpretes sugerem ao professor adequações (uso de recursos visuais, aceitação do português como segunda língua e outros) nas aulas, quando necessário?
( ) Todos
( ) A maioria
( ) Metade
( ) A minoria
( ) Nenhum

19. No seu ponto de vista, os intérpretes de Libras têm um bom relacionamento com seus professores ouvintes e vice e versa?

( ) Todos

( ) A maioria

( ) Metade

( ) A minoria

( ) Nenhum

20.Como é a sua relação com seus colegas de turma (sala de aula)? 

( ) Péssima
( ) Ruim
( ) Regular
( ) Bom
( ) Ótima

21. Os alunos ouvintes da sua turma sabem Libras?

( ) Todos

( ) A maioria

( ) Metade

( ) A minoria

( ) Nenhum

22.Os alunos ouvintes são receptivos/acolhedores quanto a sua participação em grupos ou trabalhos em sala de aula?
( ) Todos
( ) A maioria
( ) Metade
( ) A minoria
( ) Nenhum

23.Os alunos ouvintes te ajudam e esclarecem suas dúvidas das disciplinas, quando você precisa?
( ) Todos
( ) A maioria
( ) Metade
( ) A minoria
( ) Nenhum

24.Você costuma se reunir com seus colegas para estudar com eles?
( ) Sempre
( ) Frequentemente
( ) Algumas vezes
( ) Raramente
( ) Nunca

Recebido em 01/12/2016

Versão corrigida recebida em 25/05/2017

Aceito em 30/05/2017

Publicado na versão online em 03/07/2017 